\title{
Problem Solving in Early Mathematics Teaching-A Way to Promote Creativity?
}

\author{
Hanna Palmér ${ }^{1}$, Jorryt van Bommel ${ }^{2}$ \\ ${ }^{1}$ Linnaeus University, Växjö \& Kalmar, Småland, Sweden \\ ${ }^{2}$ Karlstad University, Karlstad, Värmland, Sweden \\ Email: hanna.palmer@lnu.se, jorryt.vanbommel@kau.se
}

How to cite this paper: Palmér, H., \& van Bommel, J. (2018). Problem Solving in Early Mathematics Teaching-A Way to Promote Creativity? Creative Education, 9, 1775-1793. http://dx.doi.org/10.4236/ce.2018.912129

Received: June 11, 2018

Accepted: September 4, 2018

Published: September 7, 2018

Copyright (c) 2018 by authors and Scientific Research Publishing Inc. This work is licensed under the Creative Commons Attribution-NonCommercial International License (CC BY-NC 4.0). http://creativecommons.org/licenses/by-nc/4.0/

\begin{abstract}
This article presents results from a design research study where 145 six-year-old were taught mathematics through problem solving. In the article, the implementation of the first problem solving task within the study- "the tower task"-is explored together with interviews focusing on the children's perceptions of the task as well as of problem solving in general. The results indicate that the children experienced the task as fun and accessible even though very few of them could solve it with ease. Further, the children seemed to make use of and develop their creativity by working on the problem-solving task. In the article, possibilities and limitations whit implementing problem solving in early mathematics education are discussed.
\end{abstract}

\section{Keywords}

Problem-Solving, Creativity, Mathematics, Preschool Class, Design Research

\section{Introduction}

Young children have both an interest in and a capacity for learning mathematics, and this learning starts long before formal schooling begins. For example, young children bring mathematics into their free play, a more advanced mathematics than often realised (for example Björklund, 2007; Cross, Woods, \& Schweingruber, 2009; Ginsburg, 2009; Seo \& Ginsburg, 2004). Even though there is increased awareness of the importance of mathematics for young children, views on how mathematics should be taught in early childhood settings are quite diverse (Newton \& Alexander, 2013). This diversity regards both how preschool mathematics should be designed and what constitutes an appropriate content (Palmér \& Björklund, 2016).

According to the Swedish primary school curriculum "school should stimulate 
pupils' creativity, curiosity and self-confidence, as well as their desire to explore their own ideas and solve problems (National Agency for Education, 2011: p. 11). Similar to Sweden, problem solving in mathematics is emphasised in the syllabus in many other countries. This emphasis is based on a common idea that children will develop important mathematical ideas and competences through working with problem-solving tasks (Lesh \& Zawojewski, 2007). However, many early childhood education programmes do not provide mathematical challenging activities but rather focus on basic skills (Cross et al., 2009; Perry \& Docket, 2008). Further, few studies on problem solving in mathematics have involved younger children.

In this article we present results from an intervention investigating the potential in teaching young children (six-year-old) mathematics through problem solving. The aim with the intervention was to investigate if it is possible to base children's initial mathematics education on problem solving instead of focusing on basic number words and computational procedures. By letting young children work on problem-solving solving task, we hoped to promote creativity as well as making the children experience mathematics as a tool for solving problems.

145 children from eight Swedish preschool classes at three different schools were involved in the study which was conducted through educational design research. Preschool class is an optional year of schooling that Swedish children can attend the year before formal schooling begins. The aim of the preschool class is to provide a smooth transition between preschool and primary school and to prepare children for further education. Based on this, preschool class was chosen for this study as it involves and links the content from both preschool and primary school. In several other countries children are younger than six when formal schooling starts but the focus of this article is not on what age children should be taught mathematics, but on the question of how in exploring the potential in teaching young children mathematics through problem solving.

The purpose of the study was partly to develop knowledge of implementation of problem solving in mathematics with young children who may not know how read or write, ${ }^{1}$ and partly to develop knowledge of how these young children perceive working with problem solving in mathematics. To be able to answer those questions, we conducted several problem-solving activities in the eight preschool classes and interviewed the children before and after these activities. This article will not focus on the wholeness of this study; instead the first problem-solving task that was implemented within the study will serve as an example to illustrate possibilities and limitations when implementing problem solving in early mathematics education.

\section{Mathematics in Early Childhood}

Young children's learning of mathematics is important for later mathematical

${ }^{1}$ Of course, there are young children who know how to read and write, but there is no reading or writing goals in the Swedish education system before the first grade, in primary school, when the children are seven years old. 
achievement and also for overall learning outcomes in areas such as literacy and science and technology (Cross et al., 2009; Duncan et al., 2007; Shayer \& Adhami, 2003). Children develop informal mathematical knowledge before entering school, knowledge that can be deepened and broadened by appropriate experiences (Saracho \& Spodek, 2008), and therefore young children need to be involved in "rich mathematical interactions" (Cross et al., 2009: p. 59). If early childhood mathematics education does not provide children with opportunities to explore and learn important mathematics, the children-especially economically and socially disadvantaged children-will enter school without adequate pre-knowledge in mathematics (Saracho \& Spodek, 2008).

But, with respect to young children's learning of mathematics, there is not only the question of whether or not to teach mathematics, but also questions about how the subject should be taught. Some studies have shown that regardless of socioeconomic background, young children benefit from exposure to advanced content in mathematics (Claessens, Engel, \& Curran, 2014). Other studies emphasise the importance of focusing mainly on basic number facts and on applying computational procedures (Westwood, 2011). Neither of these studies however elaborate on how this basic or advanced mathematics is to be taught. Concerning how, there are studies emphasising that young children need to be engaged in diverse and challenging mathematical activities and not "written drill" to develop their mathematical competence (Seo \& Ginsburg, 2004: p. 91). Young children spontaneously engage in problem-solving activities outside formal schooling (English, 2004a), and throughout the early years of school, children's experiences ought to include a wide range of problem-solving activities (English, 2004b). Similarly, Casey (2009) stresses that young children need to experience and to become comfortable with mathematical problem solving. Lesh and Zawojewski (2007), emphasise that working with problem solving does not rule out other elements in mathematics teaching but, on the contrary, good problem solvers seem to know more mathematics, including basic skills, and they know it differently. However, other studies argue for separating young children's work with problem solving and basic mathematical skills such as counting (Westwood, 2011). Thus, there is no consensus regarding the content or the design when teaching young children mathematics. Still, as previous shown, the school stimulating creativity, curiosity and self-confidence as well as children's desire to explore own ideas and solve problems are inscribed in the Swedish national curriculum (National Agency for Education, 2011).

\section{Problem Solving in Mathematics}

As mentioned, problem solving in mathematics is emphasized in the syllabus in many countries and there seems to be a consensus that children should be educated to become competent problem solvers (Schoenfeld, 1992). However, in many of these countries problem solving in mathematics is not integrated into mathematics teaching but is instead taught separately (Cai, 2010; English \& 
Sriraman, 2010). Yet, if children are to become successful problem solvers, problem solving needs to be an integral part of teaching and learning mathematics and not something to be added after other concepts and skills have been taught (Cai, 2010).

Even though there is "no universal agreement about what teaching mathematics through problem solving should really look like" (Cai, 2010: p. 255), there are common features. Lesh and Zawojewski (2007) write that a "task, or goal-directed activity, becomes a problem (or problematic) when the 'problem solver' $[\ldots]$ needs to develop a more productive way of thinking about the given situation" (p. 782). Thus, problem solving is close connected to creativity in the sense of finding new, for the individual, solutions to new and old problems (Craft, 2002).

Hiebert and Grouws (2002) write about "struggling with important mathematics" (p. 387) as significant in developing a deep understanding of mathematics. Struggling implies solving problems in which the mathematical ideas are understandable but not yet obtained. Understandable implies that the child understands the goal of the task whereas not yet obtained implies that the child does not have a pre-known method for solving the task. Thus, what is a problem-solving task for one child may not be a problem solving task for another child. Also struggling is close connected with creativity as one major characteristic of creativity is possibility thinking, which is about finding alternatives when obstacles are encountered (Craft, 2002).

In the study reported here, problem solving is seen as a context (Stanic \& Kilpatrick, 1989) for children to explore new mathematical methods or ideas (Nunokawa, 2005), where the children's communication, interpretations, representations, creativity and reflections are in focus. However, in the study also the problem-solving process in itself is an important issue. As mentioned, problem solving is not new in educational settings and interventions in formal school have been carried out successfully (Sowder et al, 1988; Cobb, Wood, Yackel, \& Perlwitz, 1992, Palmér \& van Bommel, 2015). It has been shown that simply teaching about problem solving or providing children with lists of rules and strategies have not increased children's problem-solving abilities (English \& Sriraman, 2010). Instead, through exploring mathematical problems children learn both problem solving and important mathematical ideas (Lesh \& Zawojewski, 2007; van Bommel \& Palmér, 2016). Common in interventions has been that the actions of the teacher have been of great importance and that it takes time for the children to adapt to the new kind of tasks (Casey, 2009; Cobb, Wood, Yackel, \& Perlwitz, 1992; Sowder et al, 1988). However, these studies have been carried out at formal school with older children. Few studies focused on problem solving in mathematics have involved children as young as those in the study presented in this article.

\section{Theoretical Perspective}

The study adopts a sociocultural approach to mathematical learning. According 
to this approach, children come to understand their world-including mathematics - through active participation in shared endeavors with other people. By participating in social activities-whereof some includes mathematics-children learn through active social interaction. Context is then not something to be acted upon but something to be interacted with and the question is not if children learn but instead what is being possible for children to learn (Vygotsky, 2012; Wertsch, 1998; Wood \& Turner-Vorbeck, 2001). Learning may then be considered as the changing relationships between an individual and the social activities in which they engage (Beach, 1999). Based on a sociocultural approach, "struggling with important mathematics" together with peers (Hiebert \& Grouws, 2002: p. 387) is connected to the zone of proximal development, implying that the mathematical problem-solving tasks are within reach-the child is able to participate in the social activity-but the activity is challenging enough to encourage changes in the child's participation. The zone of proximal development is the distance between independent problem solving and the potential development through problem solving under adult guidance or in collaboration with more capable peers (Rogoff, 2003; Wertsch, 1998).

\section{Swedish Preschool Class and Problem Solving in Mathematics}

The Swedish preschool class was implemented in 1998 to facilitate a smooth transition between preschool and primary school and to prepare children for further education. The traditions of play in preschool and of learning in school (Pramling \& Pramling-Samuelsson, 2008) made the issue of transition problematic. To facilitate a smooth transition, preschool class is supposed to work in their own way, preparing for the way of working in school, but taking their grounds in the traditions of play in preschool. Thus, the teaching in preschool class is a combination of preschool and primary school pedagogy, with play, curiosity and agency as important parts (National Agency for Education, 2014). Even though preschool class is part of the Swedish education system and included within the curriculum of obligatory schooling it until July 2018 was voluntary. However, approximately $95 \%$ of all Swedish six-year-olds have attended preschool class also before it becoming obligatory.

When the intervention was carried out the were no specific guidelines for mathematics education in preschool class. However, the aim of preschool class to provide a smooth transition to primary school and to prepare children for further education made the content of both primary school and preschool important (National Agency for Education, 2014). One goal in Swedish preschool is for every child to develop their "ability to use mathematics to investigate, reflect over and test different solutions to problems raised by themselves and others" (National Agency for Education, 2010: p. 10). According to the curriculum for primary school mathematics teaching should help children to develop their ability to "formulate and solve problems, and also reflect over and evaluate selected 
strategies and methods, models and results" (National Agency for Education, 2011: p. 63). Further, the school is responsible for ensuring that each pupil on completing compulsory school "can solve problems and transform ideas into action in a creative way" (National Agency for Education, 2011: p. 15). As such, problem solving is part of both the preschool syllabus and primary school syllabus, and so it fits naturally into the content taught in preschool class.

\section{The Study}

Educational design research implies a cyclic process of designing and testing interventions situated within an educational context and was developed to study practical and complex questions in educational settings (McKenney \& Reeves, 2012). This approach was chosen for this study based on problem solving being a content- and context-dependent process, and therefore it needs to be studied in its context (Lesh \& Zawojewski, 2007). Context is, based on the sociocultural approach, to be understood as what the children are interacting with, for example other children, tasks, tools and/or teachers. In educational design research, each design cycle includes preparing for teaching, implementation of the teaching, and finally, retrospective analysis of the teaching and learning (Cobb \& Gravemeijer, 2008). The intention of the methodology is to enable impact and transfer of research into school practice by building theories that "guide, inform, and improve both practice and research" (Anderson \& Shattuck, 2012: p. 16). As such, the purpose of design research is both to innovate and improve classroom practice and to develop design theories regarding the learning in these designed settings (Cobb \& Gravemeijer, 2008; De Corte, Verschaffel, \& Depaepe, 2009).

In this article we will not focus on the wholeness of the intervention but on one of the problem solving tasks used; the first problem-solving task that was implemented. However, when investigating children's perceptions of the intervention this lesson needs to be understood as part of a sequence of problem solving lessons.

\subsection{Participants}

Eight preschool classes from three different schools with a total of 145 children were included in the first design cycle of the study. These eight preschool classes were selected based on teachers' interest in mathematics, as shown in previous projects and professional development. Based on initial conversations with the teachers they had not been working with problem solving in mathematics in their preschool classes before but they wanted to learn how to. The teaching in the here presented part of the intervention was made by the researchers, not because the researcher would be superior to the teachers but it gave the opportunity to similar implementations in each of the eight classes and for the teachers to experience how teaching through problem solving can be carried out. The design cycle was conducted over a period of one year, working with one school at a time at different periods of the year. This means that the lessons in the first 
school (49 children) were given during the spring term, near the end of their preschool class year. The lessons in the second school ( 43 children) were given at the beginning of the autumn term, shortly after the start of their preschool class year. Finally, the lessons in the third school (53 children) were given at the end of the autumn term, in the middle of their preschool class year. We chose this spread in time to be able to detect if when during the school year was an important factor in the implementation. In the results further on, the three schools will be named the "first school", the "second school" and the "third school" based on the order presented above. The children's guardians were given written information about the study and approved their children's participation in line with the ethical guidelines provided by the Swedish Research Council (2017).

\subsection{The Lessons}

The lessons were conducted in the children's usual classrooms, and as mentioned one of the researchers acted as the teacher. For all lessons, the children were divided into groups of $11-13$ children. Teaching in Swedish preschool classes is often conducted with groups of that size. Based on the literature on problem solving and on the theoretical foundations as presented above, the lessons in the study were designed according to the following design principles (DP): The mathematical ideas in the tasks were to be understandable but the children should not previous been taught a method for solving the task. Thus, the task needs to be adaptable since a task might be a problem-solving task for one child but may not be a problem solving task for another child. (DP1). The task should be possible to solve by using different strategies (DP2). Further, the problem-solving tasks should not require the ability to read or write (DP3). To reduce the content-dependence (DP4) of our results, each task was about different mathematical ideas (3D geometry, 2D geometry, combinatory, probability, and statistics).

Each lesson lasted around 30 minutes and focused on one problem-solving task, and the lessons most often followed the same pattern. First, the children worked alone; after that they worked together with a classmate, and the lesson ended with a whole-class discussion led by the researcher. For this setting, the three dialogical patterns in teacher-child interaction (DP5), described by Rasku-Putttonen, Lerkkanen, Poikkeus and Siekkine (2012) were taken into consideration. The children were given opportunities to express their experiences (DP5a) through question and answer sequences, their diverse contributions were collectively considered (DP5b) and they were allowed space to share their ideas (DP5c). The goal of whole-class discussion led by the researcher was not just to show different strategies for solutions but to further challenge and encourage children's participation in the activity (DP2, DP5a-c).

\subsection{Observations and Interviews}

To explore possibilities and limitations with teaching young children mathematics through problem solving, the lessons were observed and paper-and-pen work 
was collected. The paper-and-pen work was analysed and categorized based on the strategies used by the children. After each lesson, the children gave a short evaluation (presented further on). The children were interviewed before and after the whole sequence of problem-solving lessons. The intention with these interviews was to investigate the children's perceptions of mathematics before the intervention and then, after the intervention, their perception of the activities.

The children were interviewed in pairs to equalise the imbalance between the researcher and the children (Alderson \& Morrow, 2011). Before the problem-solving lessons the children were asked if they knew what mathematics or problem solving was, what they thought of mathematics and whether they had mathematics in preschool class, and if so, to give examples of what they had done. The purpose of these questions was to get an indication of what kind of mathematics teaching (if any) the children were used to. In the interview after the problem-solving lessons, the children were first asked what they remembered from the lessons. After that, they were shown the problem-solving tasks they had been working with and were asked to comment on what they remembered from working with each task and how they perceived each lesson. In the interviews at the second and third school the children were also introduced to activities similar to those in the intervention. By this we wanted to investigate how they participated in similar activities several weeks after the intervention. Based on the sociocultural perspective this was a way to investigate learning as a changed relationship between an individual and the social activities in which they engaged (Beach, 1999). Finally, the children were asked whether they thought that they had learned something from the lessons.

As mentioned, one lesson will be used in this article and in the results, we will mainly focus on how the children solved this task. By comparing these solutions to children's participation in similar activities in the follow-up interview we discuss possible changes in the relationships between the children and the activities (Beach, 1999). Through the interviews, we also analyse how the children perceived the problem-solving lessons. We will not evaluate the design principles in this article since such an analysis needs to be based in all lessons within the first design cycle, not just the one focused on in this article. However, the design principles will be referred to when presenting the implementation of the task.

\subsection{Transferability}

As mentioned, problem solving is a content- and context-dependent process, which makes the question of generalisation difficult. However, we have tried to make this study less content- and context-dependent by conducting it in several different classes and by using problem-solving tasks with different mathematics content. We have also chosen to spread the time for when during the school year the implementation was conducted at each school. According to Lincoln and Guba (1985), no generalisation is possible if proper weight is given to a local context; instead, they use the word "transferability" and state that the researcher 
who knows only the sending context cannot achieve transferability. Hopefully, the result that will be presented in this article, very thoroughly describing the design and implementation of the lesson and the interviews, will provide guidance and direction for both researchers and teachers to make their own transfer of the findings.

\section{Results}

This section will be divided into two parts. First the interviews before the intervention, the chosen lesson and the follow-up interviews at the first school will be presented. After that the interventions and the interviews at the second and third schools will be presented.

\subsection{Interviews at the First School before the Intervention}

In the interviews before the sequence of problem-solving lessons, less than half of the children indicated that they knew what mathematics was. (Question: Do you know what mathematics is?) The children who indicated knowing what mathematics was most often related mathematics to numbers and counting, often within a numerical range larger than the one referred to in the curriculum for preschool. A few children mentioned examples related to geometry, and those few examples were about the names of geometrical figures. None of the children mentioned examples related to combinatory, probability, statistics or other topics in mathematics. (Questions: When do you have mathematics? Can you give some examples of mathematical activities you have done in preschool class?)

The last question in the interview was about problem solving. (Question: Do you know what problem-solving is?) Being the last question in the interview the children could have picked up the fact that problem solving and mathematics were connected; however, their responses show a social interpretation of problem and solving problems, for example:

If you start to fight. Then it is good if you solve it by yourself.

You solve the problems. Like when you erase with a rubber when you made something wrong.

\subsection{The First Task in the Intervention: "The Tower"}

In the first lesson the children were handed a picture (DP3) of a tower (Figure 1). The question asked was "How many blocks will you need to build the tower?" The task deals with a two-dimensional representation of a three-dimensional figure. Counting is required $(1,2,3 \ldots)$, however very limited. No calculation is required, but addition can be used, for example $6+4$ as adding six blocks in the front and four blocks in the back, or $3+2+2+1+1+1$ as adding one bar at the time.

The task is about geometry, which, through Froebel's gifts, was one of the first areas of mathematics that was systematically taught to young children (Perry \& 


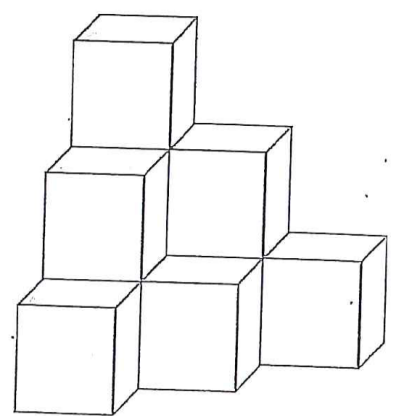

Figure 1. The picture of a tower given to the children in the first lesson. ${ }^{2}$

Docket, 2008). Learning about two-dimensional and three-dimensional shapes is not just about recognising and naming them but also about composing and decomposing, analysing and recognising their properties and features. Further, composing and decomposing is a foundation for later reasoning about fractions, area and volume (Cross et al., 2009).

To be able to determine how many blocks they will need to build the tower the children have to imagine the tower from a different perspective. Imagining an object from a different perspective is related to spatial thinking, which is fundamental in mathematics. Spatial thinking makes it possible to mentally compare, rotate, hold in mind and conceptualise relationships within a mathematical problem and to transform objects. Further, spatial skills have been shown to be a predictor for further mathematical achievement, not only in specific mathematical domains such as geometry and measurement but also in problem solving. Even though children start to develop spatial thinking early, it is heavily dependent on children having relevant experiences. In these experiences, communication and spatial activities have proven to be highly influential (Cross et al., 2009; Kersh, Casey, \& Mercer Young, 2008).

\section{3. "The Tower" at the First School}

As mentioned, there were 49 children at the first school, but only 44 were present when working with the tower task. First, the children were to draw or write on the paper how many blocks they would need to build the tower (DP5a). They did this in different ways (DP2), for example by using numeral symbols, lines, arrows etc. (Figure 2). Only one child initially said that he would need 10 blocks to build the tower. Three children initially said that they would need eight blocks to build the tower. All these used number symbols when writing their answer. The remaining 40 children initially said that they would need six blocks to build the tower. These children used different representations; arrows, number symbols and lines (DP2). Evaluating this first part of the lesson all children's actions gave us the impression them understanding the goal of the task and it appeared to have been a problem-solving task for all but one child (DP1) in the sense of them needing to develop a more productive way of participating in the activity.

${ }^{2}$ The task is taken from http://ncm.gu.se/kangaru. 


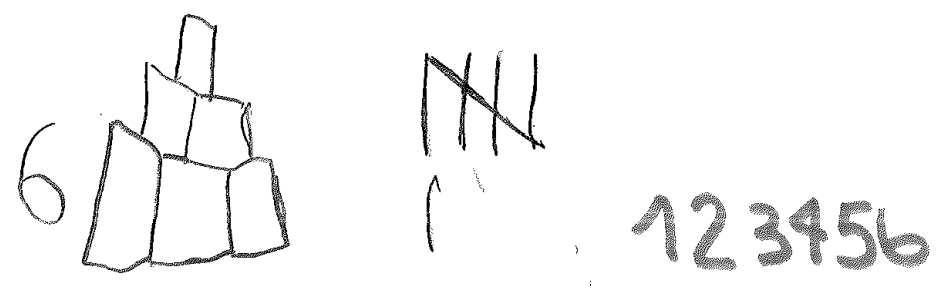

Figure 2. Examples of paper-and-pencil work.

After children had worked on their own (DP5a), they were to discuss their solutions with a classmate (DP5a). When the children were divided into pairs, the child who initially said 10 blocks was put together with a child who initially said eight blocks. These two were given an extra task: they were asked whether there could be more than 10 blocks in the tower in the picture (DP1).

\subsubsection{Building the Tower}

After discussing their solutions in pairs, the same pairs of children were to build the tower using manipulatives (DP3). First, they built with blocks, and after that they built using a building programme on a tablet computer. When building the tower with blocks the children found the need for (at least) 10 blocks, and discussions were held about which blocks were "being hidden" in the picture. In most cases, it took quite a long time for the children to build the tower since they wanted to use only six blocks, in line with their first solution. After all groups had built the tower with blocks and on the tablet computers, they were gathered for the whole-class discussion (DP5a, b, c). As such, the children discussed the task and their solutions both in pairs and as a whole class together with the researcher. In the whole-class discussion one aim was to help children to connect the different representations (DP5b) of the tower (picture-building blocks-tablet computer) as well as offer proper use of mathematical language connected to solving the task (for example rotate, perspective, behind). The different ways of solving the problem were put forward (DP2).

\subsubsection{Children's Evaluation}

The lesson ended with the children evaluating the activity individually. On the back of their papers they were to evaluate the difficulty of the task by choosing one of three options, describing the task as very easy, hard at the beginning, but now they understand its solution; or hard, and they do not understand its solution. They were also to choose between drawing a happy, neutral or sad face indicating how they felt during the activity. Their evaluation of the tower task is presented (Table 1). Thus, even though 40 of the 44 children initially did not manage to solve the problem and thought that they would need six blocks to build the tower, 18 evaluated the task as very easy. 21 children evaluated the task as hard at the beginning, but now I understand its solution. At the same time they considered the task to be fun. Similar the children who evaluated the task as hard and did not understand its solution evaluated the task as fun. 
Table 1. Children's evaluation of the tower task.

\begin{tabular}{|c|c|c|c|}
\hline & $\begin{array}{c}\text { The task was very } \\
\text { easy }\end{array}$ & $\begin{array}{c}\text { The task was hard at the } \\
\text { beginning, but now I } \\
\text { understand its solution }\end{array}$ & $\begin{array}{c}\text { The task was hard, and I } \\
\text { do not understand its } \\
\text { solution }\end{array}$ \\
\hline happy face & 18 & 21 & 2 \\
\hline $\begin{array}{c}\text { Neutral face } \\
\text { sad face }\end{array}$ & & 3 & \\
\hline
\end{tabular}

\subsubsection{Interviews at the First School after the Intervention}

As mentioned the follow-up interviews were conducted after the whole sequence of lessons within the intervention; thus about six to eight weeks after the tower lesson. First the children were asked what they remembered from all the lessons. (Question: What do you remember of what we have been doing when I have been here?) The majority of the children remembered a lot and many of them mentioned the tower task, giving quite general descriptions of it focused on the building of the tower.

When we were to build a tower.

We built with blocks. You were to build a tower.

After that, the children were shown the different tasks they had been working with, and were asked to comment on what they remembered from working with each of them. (Question: Do you remember this task? If they did, we continued with two more questions; do you remember how you solved it? What did you think of that task?) When they were shown and asked to comment on the tower task, several children remembered their own solution and the final need for (at least) 10 blocks, and they often showed how to count the blocks during the interview. Their answers indicated them having developed a more productive way of participating in the activity.

Because it was [blocks] behind also. You needed ten.

You just have to do like this. That one is three. (Points at the back part of the tower on the picture.) One, two, three, four, five, six, seven, eight, nine, ten. (Points at both the visible and hidden blocks on the picture as he counts.) Really easy. And quite fun too.

Their answers indicated perceptions of the task in line with their evaluation directly after the lesson (Table 1).

I thought it was hard. You could see six, but it was ten.

It was ten. Good. Not that hard. It took just a little while.

Difficult and funny! First I did not understand how you were supposed to build the tower. It was ten because there were [blocks] behind.

\subsection{The Second and Third Schools}

The interviews before the intervention at the second and third interviews indicated these children having similar experiences of mathematics in preschool class as the children at the first preschool class, implying few children indicated 
knowing what mathematics or problem-solving was and those who indicated knowing what mathematics was most often related mathematics to numbers and counting. The tower task was conducted similarly at the second and third schools, as the result of the first school did not have any implications for a re-design of the task and the evaluation of the design principles was not to be done until after the whole design cycle being conducted at these three schools.

Similar to the first school, very few children initially gave an answer other than six blocks when they were only looking at the picture of the tower. Also, the paper-and-pen work showed the same spread of representations. And, at the end of the lesson, after building with blocks and on the tablet computer, the children agreed on the need for more blocks to build the tower. Thus, the time for when during the school year the implementation was conducted at the schools do not seem to have influenced the results. When the children were shown the tower in the follow-up interview some weeks later, the children's remarks were similar to those of the children at the first school, describing their own solutions and indicating that they had been surprised. Just like the interviews at the first school, these interviews gave information on whether or not the children remembered the answers to the specific problems. However, in the follow-up interviews at the second and third schools we also added extra questions that were related to the mathematical idea of each lesson. This was to see how the children participated in similar activities as those in the intervention and investigate if we could see any changes in the relationships between the children and the activities. To investigate how the children now would participate in an activity similar to "the tower" they were shown a picture of a new tower (Figure 3).

At the second school, 29 children answered that four cubes were needed and pointed out reasons without being asked. Eight of them said three at first but changed their answer to four immediately when explaining their reasoning.

In the other tower there were four cubes at the backside, here there is only one, so four in total.

You need one underneath the top one, otherwise it would collapse.

It has to be four, but it could be five, you cannot see the other one.

Nine children still only counted the cubes that were visible, and five children said five or six cubes were needed. Thus, at least 29 of 38 children had developed a more productive way of participating in the activity.

At the third school, unfortunately only 38 children (out of 53) were present on the day of the follow-up interview. Nine of these counted the number of cubes in the new tower correctly, and 12 gave answers involving the idea of "cubes behind". The majority of these children used their fingers when counting both visible and hidden cubes. Some children, however, counted stacks instead, for example:

There behind there are three. Three, six, ten! Twelve I mean! Three on each side. No, there is one missing. It must be eleven.

Ten. No, eleven. Is six plus six eleven? (The researcher answers that six plus six is twelve.) Then it is eleven. Otherwise there will not be a hole here. 


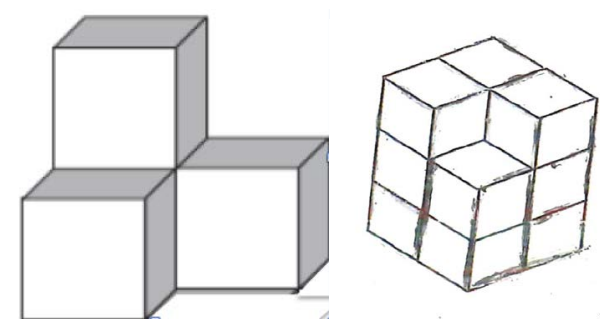

Figure 3. The towers shown to the children in the follow-up interviews. The tower to the left was used in the interview at the second school; the tower to the right was used in the interview at the third school.

Fourteen children still only counted the visible cubes, and three children did not count but just gave an incorrect answer without motivation. Thus, at least 21 of 38 children had developed a more productive way of participating in the activity. Together the follow-up interviews at the second and third school indicate that several of the children had changed their way of participating in this activity.

\section{Discussion}

How we arrange activities influences what children are invited to participate in and consequently their possibilities of learning mathematics (Rogoff, 2003; Wertsch, 1998) where the aim of this study was to explore possibilities and limitations with teaching young children mathematics through problem solving. As mentioned, the traditions of play in preschool and of learning in school are supposed to be integrated in Swedish preschool class (Pramling \& Pramling-Samuelsson, 2008) and one could ask about what kind of lesson the "tower task" is? The intention is absolutely learning, however in quite playful setting within the frames of "stimulat [ing] pupils' creativity, curiosity and self-confidence, as well as their desire to explore their own ideas and solve problems" (National Agency for Education, 2011: p.11).

Common in several previous interventions of problem solving has been that that it has taken time for the children to adapt to the new kind of tasks (Casey, 2009; Cobb, Wood, Yackel, \& Perlwitz, 1992; Sowder et al., 1988). This however do not seem to be the case in this study. At the beginning of the "tower lesson" very few children indicated having participated in activities providing them with three-dimension experiences of towers. Children's answers in the follow-up interviews indicate that several children through the lesson changed their ways of participating in similar activities. In the interviews the children explain their own and others' solutions and explain why (at least) 10 blocks were needed to build the tower. Several of them talk differently about the number of blocks in the tower and they also express how they themselves have participated differently before (for example: "Before I didn't know that there should be three blocks under"). Sometimes the children do not express the right number of blocks in the follow-up interviews but often their answers involve elements focused on the presence of blocks that are not visible in the picture. 
As mentioned, context is to be understood as what the children are interacting with, for example other children, tools and/or teachers. Regarding tools, using manipulatives enhances mathematical knowledge for young children (Cross et al., 2009), and digital technology has been shown to be effective when illustrating transformations and rotations of geometrical objects (Sarama \& Clements, 2009). Even though few children were able to solve the task from the beginning, after building the tower with blocks and on the tablet computer they were able to compare and rotate the tower as well as make connections between the picture and the blocks. Building on the tablet computer in particular seemed to help the children connect the different representations of the tower. For example, one child said that "if you had been able to rotate the first picture you would have seen the other blocks". Thus, the tablet computer seems to have developed children's possibilities to participate in the activity.

Even though only four of the children (in all three schools together) were able to solve the tower task from the beginning, the majority of children evaluated the task as fun and accessible. Only two of the children (all three schools) evaluated the "tower task" with the alternative "the task was hard, and I do not understand its solution". Problem solving tasks are often defined as tasks where the child "needs to develop a more productive way of thinking about the given situation" (Lesh \& Zawojewski, 2007: p. 782) or as tasks where the child is "struggling with important mathematics" (Hiebert \& Grouws, 2002). However, this does not seem to imply neither boring nor difficult for the children. Not succeeding from the beginning does not seem to be necessary for children to evaluate a task as fun and accessible. Based on the children's perspective, a problem-solving task can be both fun and accessible even if one does not know how to solve it from the beginning. All but three children drew happy faces when evaluating the lesson presented in this article and none drew a sad face. Of course, this could be an expression of wanting to please the researchers, but when considered in connection with the interviews, the happy faces seem to reflect how the children perceived the lesson.

\section{Conclusion}

This study indicates that young children are capable of working with problem solving and that they perceive it as fun and accessible. Both the lessons and the interviews show that young children are competent, both in terms of problem solving and in terms of reflecting on their own learning and the mathematics lessons they encounter. Based on the intervention, problem solving seems to be a possible starting point for early mathematics. The young children do not seem to need any kind of special preparation to be involved in this kind of mathematics teaching and learning but are creative and competent, both in terms of problem solving and in terms of reflecting on their own learning. Based on the children's perspective, a problem-solving task can be both fun and accessible even if one does not know how to solve it from the beginning. Young children seem to ap- 
preciate the challenge and creativity involved in problem solving and they learn mathematics. So far in the study, we have found no negative outcomes of the problem-solving approach, quite the opposite the results indicate that problem solving is a way to cover both basic and advanced mathematics and that the approach makes it possible for young children to participate on their conditions. Based on these results we do not claim that this is the only way that all mathematics in preschool class is to be taught, but we do claim that it is one possible way. As mentioned, problem solving is a content- and context-dependent process why further research in different contexts using problem-solving tasks focusing on different content is needed to make any further generalisations.

\section{Conflicts of Interest}

The authors declare no conflicts of interest regarding the publication of this paper.

\section{References}

Alderson, P., \& Morrow, V. (2011). The Ethics of Research with Children and Young People: A Practical Handbook. London: SAGE Publications. https://doi.org/10.4135/9781446268377

Anderson, T., \& Shattuck, J. (2012). Design-Based Research: A Decade of Progress in Education Research? Educational Researcher, 41, 16-25.

https://doi.org/10.3102/0013189X11428813

Beach, K. (1999). Consequential Transitions: A Sociocultural Expedition beyond Transfer in Education. American Educational Research Association, 24, 101-139.

https://doi.org/10.2307/1167268

Björklund, C. (2007). Hållpunkter för lärande. Småbarns möten med matematik. [Critical Conditions of Learning. Toddlers Encountering Mathematics]. Åbo: Abo Akademi University Press.

Cai, J. (2010). Commentary on Problem Solving Heuristics, Affect, and Discrete Mathematics: A Representational Discussion. In B. Sriraman, \& L. English (Eds.), Theories of Mathematics Education: Seeking New Frontiers (pp. 251-258). Dordrecht: Springer. https://doi.org/10.1007/978-3-642-00742-2_25

Casey, B. (2009). Applying Developmental Approaches to Learning Math. In O. A. Barbarin, \& B. H. Wasik (Eds.), Handbook of Child Development and Early Education: Research to Practice (pp. 478-498). New York: The Guilford Press.

Claessens, A., Engel, M., \& Curran, C. F. (2014). Academic Content, Student Learning, and the Persistence of Preschool Effects. American Educational Research Journal, 51, 403-434. https://doi.org/10.3102/0002831213513634

Cobb, P., \& Gravemeijer, K. (2008). Experimenting to Support and Understand Learning Processes. In A. E. Kelly., R. A. Lesh, \& J. Y. Baek (Eds.), Handbook of Design Research Methods in Education: Innovations in Science, Technology, Engineering, and Mathematics Learning and Teaching (pp. 68-95). New York: Routledge.

Cobb, P., Wood, T., Yackel, E., \& Perlwitz, M. (1992). A Follow-Up Assessment of a Second-Grade Problem-Centered Mathematics Project. Educational Studies in Mathematics, 23, 483-504. https://doi.org/10.1007/BF00571469

Craft, A. (2002). Creativity and Early Years Education. London: Continuum.

Cross, C. T., Woods, T. A., \& Schweingruber, H. (2009). Mathematics Learning in Early 
Childhood: Paths toward Excellence and Equity. Washington DC: National Research Council of the National Academics.

De Corte, E., Verschaffel, L., \& Depaepe, F. (2009). Enhancing Mathematical Problem Solving in Primary School Children: Lessons from Design Experiments. In O. A. Barbarin, \& B. H. Wasik (Eds.), Handbook of Child Development and Early Education: Research to Practice (pp. 521-543). New York: The Guilford Press.

Duncan, G. J., Dowsett, C. J., Claessens, A., Magnuson, K., Huston, A. C., Klebanov, P., Pagani, L. S., Feinstein, L., Engel, M., Brooks-Gunn, J., Sexton, H., Duckworth, K., \& Japel, C. (2007). School Readiness and Later Achievement. Developmental Psychology, 43, 1428-1446. https://doi.org/10.1037/0012-1649.43.6.1428

English, L. (2004a). Mathematical and Analogical Reasoning in Early Childhood. In L. English (Ed.), Mathematical and Analogical Reasoning of Young Learners (pp. 1-22). New Jersey: Lawrence Erlbaum Associates Inc.

English, L. (2004b). Promoting the Development of Young Children's Mathematical and Analogical Reasoning. In L. English (Ed.), Mathematical and Analogical Reasoning of Young Learners (pp. 201-213). New Jersey: Lawrence Erlbaum Associates Inc.

English, L., \& Sriraman, B. (2010). Problem Solving for the 21st Century. In B. Sriraman, \& L. English (Eds.), Theories of Mathematics Education: Seeking New Frontiers (pp. 263-290). Dordrecht: Springer. https://doi.org/10.1007/978-3-642-00742-2_27

Ginsburg, H. P. (2009). Early Mathematics Education and How to Do It. In O. A. Barbarin, \& B. H. Wasik (Eds.), Handbook of Child Development and Early Education: Research to Practice (pp. 403-428). New York, NY: The Guilford Press.

Hiebert, J., \& Grouws, D. A. (2002). The Effects of Classroom Mathematics Teaching on Students Learning. In F. K. Lester (Ed.), Second Handbook of Research on Mathematics Teaching and Learning (pp. 371-404). Charlotte: National Council of Teachers of Mathematics and Information Age Publishing.

Kersh, J., Casey, B. M., \& Mercer Young, J. (2008). Research on Spatial Skills and Block Building in Girls and Boys. In O. N. Saracho, \& B. Spodek (Eds.), Contemporary Perspectives in Early Childhood Education (pp. 233-251). Charlotte, NC: Age Publishing Inc.

Lesh, R., \& Zawojewski, J. (2007). Problem Solving and Modeling. In F. K. Lester (Ed.), Second Handbook of Research on Mathematics Teaching and Learning (pp. 763-799). Charlotte: National Council of Teachers of Mathematics and Information Age Publishing.

Lincoln, Y. S., \& Guba, E. G. (1985). Naturalistic Inquiry. Beverly Hills, CA: SAGE Publications.

National Agency for Education (2010). Curriculum for the Preschool Lpfö98. Stockholm: National Agency for Education.

National Agency for Education (2011). Curriculum for the Primary School, Preschool Class and Leisure Time Center 2011. Stockholm: National Agency for Education.

National Agency for Education (2014). Preschool Class: Assignment, Content and Quality. Stockholm: Swedish National Agency for Education.

Newton, K. J., \& Alexander, P. A. (2013). Early Mathematics Learning in Perspective: Eras and Forces of Change. In L. D. English, \& J. T. Mulligan (Eds.), Reconceptualizing Early Mathematics Learning (pp. 5-28). Dordrecht: Springer. https://doi.org/10.1007/978-94-007-6440-8_2

Nunokawa, K. (2005). Mathematical Problem Solving and Learning Mathematics: What We Expect Students to Obtain. Mathematical Behavior, 24, 325-340. 
https://doi.org/10.1016/j.jmathb.2005.09.002

Palmér, H., \& Björklund, C. (2016). Different Perspectives on Possible Desirable Plausible Mathematics Learning in Preschool. Nordic Studies in Mathematics Education, 21, 177-191.

Palmér, H., \& van Bommel, J. (2015). How to Solve It: Students' Communication When Problem Solving in Groups. In H. Silfverberg, T. Kärki, \& M. S. Hannula (Eds.), Nordic Research in Mathematics Education: Proceedings of NORMA14 (pp. 329-338). Turku: University of Turku.

Perry, B., \& Dockett, S. (2008). Young Children's Access to Powerful Mathematical Ideas. In L. D. English (Ed.), Handbook of International Research in Mathematics Education (pp. 75-108). New York, NY: Routledge.

Pramling, N., \& Pramling Samuelsson, I. (2008). Identifying and Solving Problems: Making Sense of Basic Mathematics through Storytelling in the Preschool Class. International Journal of Early Childhood, 40, 65-79. https://doi.org/10.1007/BF03168364

Rasku-Puttonen, H., Lerkkanen, M.-K., Poikkeus, A.-M., \& Siekkin, M. (2012). Dialogical Patterns of Interaction in Pre-School Classrooms. International Journal of Educational Research, 53, 138-149. https://doi.org/10.1016/j.ijer.2012.03.004

Saracho, O. N., \& Spodek, B. (2008). Trends in Early Childhood Mathematics Research. In O. N. Saracho, \& B. Spodek (Eds.), Contemporary Perspectives in Early Childhood Education (p. 7). Charlotte, NC: Age Publishing Inc.

Sarama, J., \& Clements, D. H. (2009). "Concrete” Computer Manipulatives in Mathematics Education. Child Development Perspectives, 3, 145-150.

https://doi.org/10.1111/j.1750-8606.2009.00095.x

Schoenfeld, A. (1992). Learning to Think Mathematically: Problem Solving, Metacognition, and Sense-Making in Mathematics. In A. Douglas Grouws (Ed.), Handbook for Research on Mathematics Teaching and Learning (pp. 334-370). New York, NY: MacMillan.

Seo, K.-H., \& Ginsburg, H. P. (2004). What Is Developmentally Appropriate in Early Childhood Mathematics Education? Lessons from New Research. In D. H. Clements, \& J. Sarama (Eds.), Engaging Young Children in Mathematics (pp. 91-104). Mahwah: Erlbaum Associates Inc.

Shayer, M., \& Adhami, M. (2003). Realising the Cognitive Potential of Children 5-7 with a Mathematics Focus. International Journal of Educational Research, 39, 743-775. https://doi.org/10.1016/j.ijer.2004.10.005

Sowder, J., Sowder, L., Cobb, P., Yackel, E., Wood, T., Wheatley, G., \& Merkel, G. (1988). Creating a Problem-Solving Athmosphere. The Arithmetic Teacher, 36, 46-47.

Stanic, G. M., \& Kilpatrick, J. (1989). Historical Perspectives on Problem Solving in the Mathematics Curriculum. In R. I. Charles, \& E. A. Silver (Eds.), The Teaching and Assessing of Mathematical Problem Solving (pp. 1-22). Reston, VA: NCTM/Lawerance Erlbaum Associates.

Swedish Research Council (2017). Good Custom in Research. Stockholm: Vetenskapsrådet.

van Bommel, J., \& Palmér, H. (2016). Young Children Exploring Probability: With Focus on Their Documentations. Nordic Studies in Mathematics Education, 21, 95-114.

Vygotsky, L. (2012). Thought and Language. London: MIT Press.

Wertsch, J. V. (1998). Mind as Action. New York, NY: Oxford University Press, Inc.

Westwood, P. (2011). The Problem with Problems: Potential Difficulties in Implementing 
Problem-Based Learning as the Core Method in Primary School Mathematics. Australian Journal of Learning Difficulties, 16, 5-18.

https://doi.org/10.1080/19404158.2011.563475

Wood, T., \& Turner-Vorbeck, T. (2001). Extending the Conception of Mathematics Teaching. In T. Wood, B. Scott Nelson, \& J. Warfield (Eds.), Beyond Classical Pedagogy. Teaching Elementary School Mathematics (pp. 185-208). Mahwah, NJ: Lawrence Erlbaum Associates. 